\title{
CORRIGENDUM
}

\section{Effects of pre- and postnatal maternal stress on infant temperament and autonomic nervous system reactivity and regulation in a diverse, low-income population-CORRIGENDUM}

\author{
NICOLE R. BUSH,${ }^{a}$ KAREN JONES-MASON, ${ }^{a}$ MICHAEL COCCIA,${ }^{a}$ ZOE CARON,${ }^{a}$ ABBEY ALKON,${ }^{a}$ \\ MELANIE THOMAS, ${ }^{b}$ KIM COLEMAN-PHOX, ${ }^{a}$ PATHIK D. WADHWA, ${ }^{c}$ BARBARA A. LARAIA, ${ }^{d}$ \\ NANCY E. ADLER, ${ }^{a}$ AND ELISSA S. EPEL ${ }^{a}$ \\ ${ }^{a}$ University of California, San Francisco; ${ }^{b}$ Zuckerberg San Francisco General Hospital and Trauma Center; \\ ${ }^{c}$ University of California, Irvine; and ${ }^{d}$ University of California, Berkeley
}

doi:10.1017/S0954579417001237, published by Cambridge University Press, 22 November 2017

We recently identified two important errors in the discussion in our original article. The first is in the first full sentence on page 1564, where higher in temperamental surgency should be lower, and the second is in the first sentence in the second

\section{Reference}

Bush, N. R., Jones-Mason, K., Coccia, M., Caron, Z., Alkon, A., Thomas, M., ... Epel, E. S. (2017). Effects of pre- and postnatal maternal stress on infant temperament and autonomic nervous system reactivity and regulation in a paragraph on page 1566, where high surgency should be low. Both corrected pages are reprinted herein. We regret these errors and any problems they may have caused.

diverse, low-income population. Development and Psychopathology, 29 1553-1571. doi:10.1017/S0954579417001237 